\title{
Rancang Bangun Sistem Peminjaman dan Manajemen Aset Laboratorium Berbasis Implementasi RFID dan Aplikasi Web
}

\author{
Darwin $^{1}$, Nova Eka Budiyanta ${ }^{2}$ \\ 1,2 Program Studi Teknik Elektro, Universitas Katolik Indonesia Atma Jaya, Jakarta, Indonesia \\ ${ }^{1}$ darwinsantoso55@gmail.com, ${ }^{2}$ nova.eka@atmajaya.ac.id* \\ * corresponding author
}

\begin{tabular}{|c|c|}
\hline ABSTRACT & Article Info \\
\hline $\begin{array}{l}\text { Laboratories in university are one of the most essential facilities needed for } \\
\text { academic activities. However, because of the Covid-19 pandemic, there is now } \\
\text { restriction to access university laboratories. Students have lost their access to } \\
\text { laboratory equipment. Based on this problem, a web application for equipment } \\
\text { booking and laboratory asset management is made. The web application uses } \\
\text { RFID technology with NodeMCU ESP8266 as its microcontroller, and } \\
\text { CodeIgniter } 4 \text { framework. The web application is evaluated by feature validation } \\
\text { by the laboratory assistant head, white-box test and black-box test. White-box } \\
\text { test uses Apache JMeter } 5.3 \text { to do load testing. The black-box test produces a } \\
\text { functionality percentage of } 82 \% \text {, and from the white-box and feature validation } \\
\text { we can conclude that the web application works well and is ready to be used. }\end{array}$ & $\begin{array}{r}\text { Article history } \\
\text { Received: Nov. } 4^{\text {th }}, 2021 \\
\text { Revised: Nov. } 28^{\text {th }}, 2021 \\
\text { Accepted: Nov. } 29^{\text {th }}, 2021 \\
\text { Keywords } \\
\text { RFID, } \\
\text { Manajemen Aset, } \\
\text { Laboratorium, } \\
\text { Mikrokontroller, } \\
\text { Sistem Peminjaman Alat. }\end{array}$ \\
\hline ABSTRAK & \\
\hline $\begin{array}{l}\text { Laboratorium universitas merupakan salah satu fasilitas yang penting dalam } \\
\text { kegiatan akademik. Namun dengan adanya pandemi Covid-19, akses } \\
\text { laboratorium pada universitas dibatasi dan mahasiswa kehilangan akses } \\
\text { penggunaan alat laboratorium. Berdasarkan masalah ini, aplikasi web } \\
\text { peminjaman alat secara online dan manajemen laboratorium dibuat. Aplikasi } \\
\text { berbasis web dilengkapi dengan RFID tapping tag pada alat, NodeMCU } \\
\text { ESP8266 sebagai mikrokontroler dan CodeIgniter } 4 \text { untuk framework } \\
\text { pengembangan aplikasi web tersebut. Sistem diuji dengan white-box test } \\
\text { menggunakan Apache JMeter } 5.3 \text { sebagai load testing tool dan black-box test } \\
\text { untuk menguji kelayakan aplikasi web seperti aspek fungsionalitas dan tampilan } \\
\text { aplikasi, Hasil dari black-box test disimpulkan dari persentase kelayakan } \\
\text { fungsional sistem yang diperoleh sebesar } 82 \% \text {. Dari hasil pengujian dapat dilihat } \\
\text { bahwa sistem website peminjaman dapat bekerja dengan baik dan layak untuk } \\
\text { digunakan. }\end{array}$ & \\
\hline
\end{tabular}

\section{PENDAHULUAN}

Laboratorium pada Universitas merupakan salah satu fasilitas yang penting dalam kegiatan akademik Universitas, terutama pada fakultas yang membutuhkan alat-alat untuk praktikum. Laboratorium digunakan sebagai tempat untuk menyimpan alat-alat penting untuk praktikum, juga sebagai tempat untuk melaksanakan praktikum tersebut. Di laboratorium dapat dilaksanakan kegiatan untuk meneliti maupun mencari jawaban dari ilmu yang dipelajari oleh mahasiswa (Ariesta, 2011: 62-68). Terutama untuk mahasiswa tahun akhir, laboratorium digunakan untuk tempat melakukan pembuatan tugas akhir karena 
adanya alat-alat yang tidak bisa digunakan dari rumah atau dibeli.

Namun dikarenakan pandemi Covid-19, mahasiswa dihimbau untuk melakukan online learning dari rumah. Seperti pada Program Studi Teknik Elektro, Universitas Katolik Indonesia Atma Jaya Jakarta, mahasiswa tidak lagi melakukan kegiatan pembelajaran di kampus. Hal tersebut dapat dilakukan untuk kegiatan akademik pada kelas, namun sulit untuk kegiatan pada laboratorium karena memerlukan alat. Mahasiswa tahun akhir juga mendapat kesulitan dari online learning, karena akses penggunaan laboratorium dibatasi oleh Universitas. Selama pandemi, mahasiswa harus datang langsung ke kampus untuk menggunakan alat tersebut dimana akses mahasiswa untuk menggunakan peralatan laboratorium menjadi sangat terbatas.

Berdasarkan keterbatasan akses mahasiswa terhadap penggunaan peralatan laboratorium tersebut, sistem ini dibuat untuk memungkinkan dan mempermudah proses peminjaman alat pada laboratorium untuk mahasiswa Teknik Elektro Unika Atma Jaya,

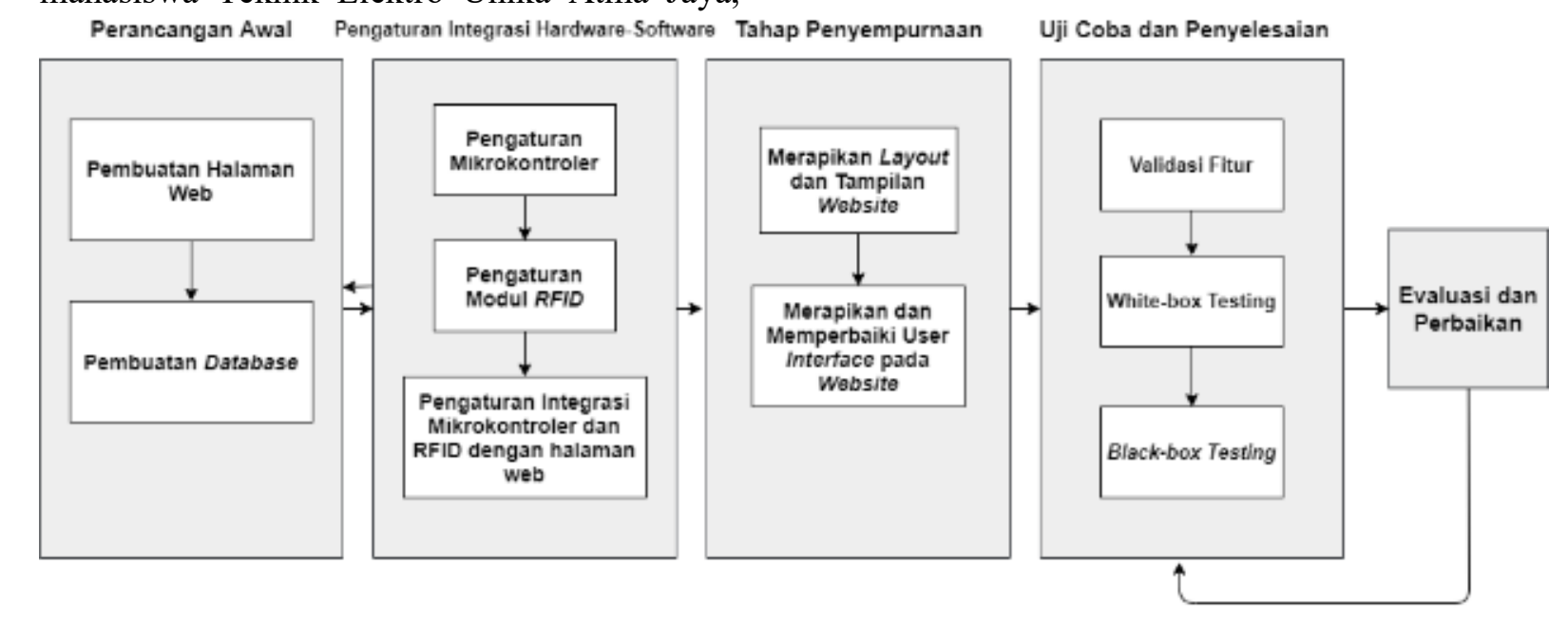

Gambar 1. Alur Pembuatan Sistem terutama mahasiswa tingkat akhir selama masa pandemi tanpa harus datang ke kampus. Dengan mengimplementasikan sistem ini, mahasiswa dapat melakukan peminjaman alat laboratorium dengan mudah dan pihak Universitas dapat mendata peminjaman yang dilakukan serta mempunyai manajemen stok alat pada laboratorium yang lebih teratur.

\section{METODE}

Solusi yang ditawarkan pada studi ini adalah pengembangan aplikasi web yang digunakan untuk melakukan peminjaman barang laboratorium secara online dan juga peminjaman di tempat, serta manajemen inventori barang laboratorium. Alur pembuatan sistem meliputi Perancangan Awal, Pengaturan Integrasi Hardware-Software, Tahap Penyempurnaan, Uji Coba dan Penyelesaian, serta Evaluasi dan Perbaikan. Pada tahap Evaluasi dan Perbaikan, sistem kembali diuji jika masih ditemukan kesalahan ataupun kurang ketersesuaian dengan alur kerja peminjaman peralatan laboratorium. Secara lebih detail, alur pembuatan sistem dapat dilihat pada Gambar 1 .
Sistem yang dikembangkan mencakup aplikasi web terintegrasi dengan perangkat keras berupa RFID Reader RC522 dan NodeMCU ESP8266 sebagai mikrokontroler untuk menerima UID dari tag RFID dan selanjutnya dikirim ke database untuk ditampilkan pada website. Hubungan antara perangkat keras dan perangkat lunak pada sistem dijelaskan dengan diagram blok pada Gambar 2. 


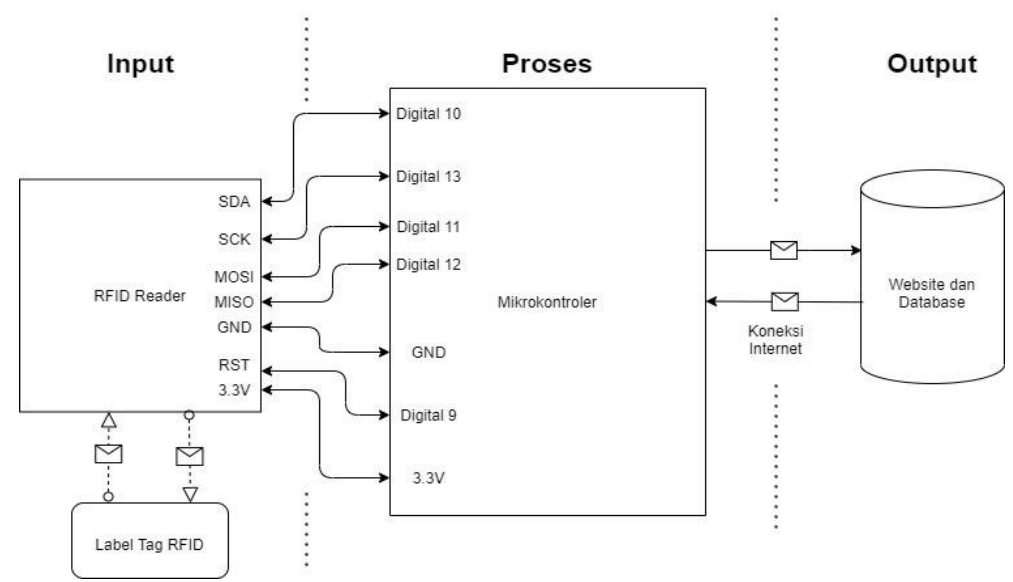

Gambar 2. Block Diagram Sistem

Pada Block Diagram terlihat bahwa terdapat arah pertukaran data yang terjadi dalam sistem, dan hubungan antar komponen. Reader RFIDdigunakan sebagai komponen yang menerima masukan kode barang dari tag RFID saat pengguna melakukan tapping, dan mikrokontroler sebagai komponen untuk mengelola data tersebut. Website dan database berfungsi untuk menampilkan data yang sudah dikelola oleh mikrokontroler. Label tag RFID berkomunikasi dengan reader saat didekatkan, lalu data terkirim dari melalui pin yang sudah dihubungkan dengan mikrokontroler. Setelah data RFID diterima pada mikrokontroler, selanjutnya data dikirimkan menuju database melalui protokol HTTP (Fielding R., dkk, 2009) dan jaringan internet.

Tahap perancangan paling awal adalah pembuatan website dan database. Semua halaman website yang sudah direncanakan dibuat terlebih dahulu dan dipastikan semua elemen pada halaman dapat ditampilkan. Setelah itu perancangan database dimulai sesuai dengan Entity Relationship Diagram (ERD) pada Gambar 3. Pada ERD terdapat 12 tabel yang berhubungan dengan satu sama lain yang menunjukkan keterkaitan data pada sistem.

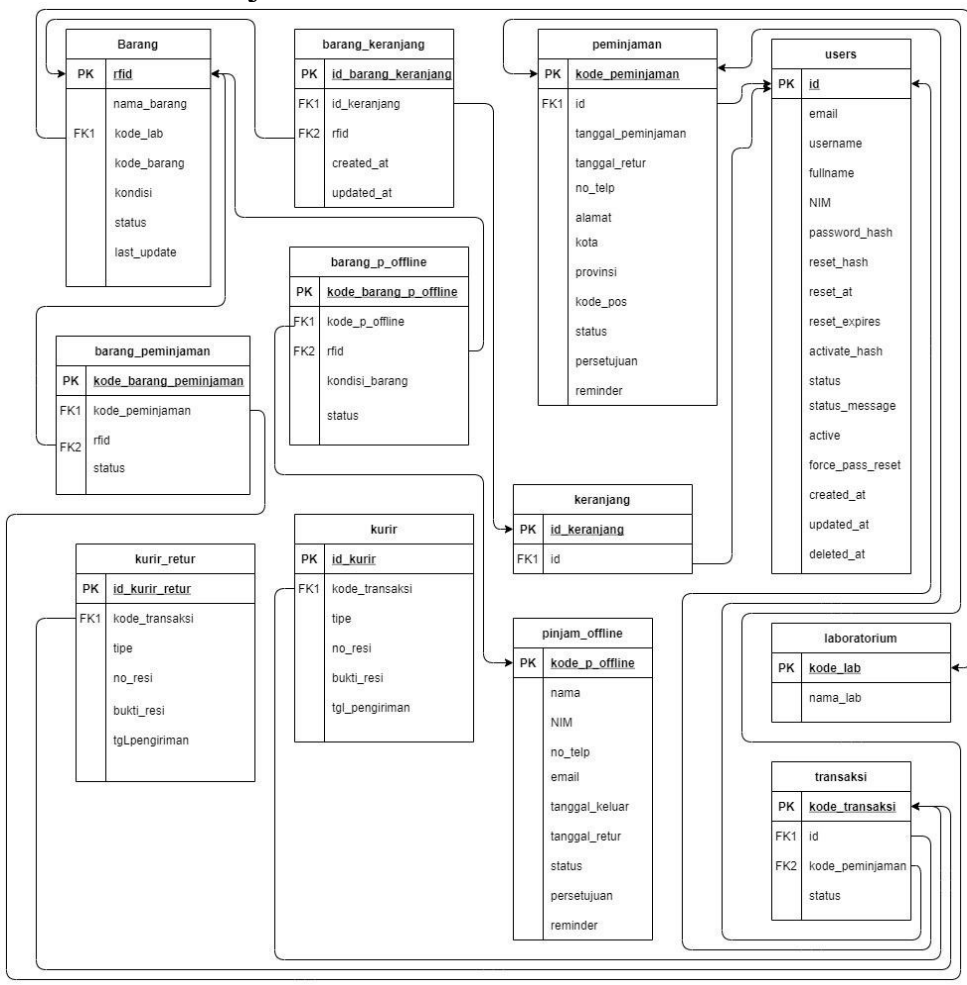

Gambar 3. Entity Relationship Diagram dari Sistem 
Setelah halaman web dan perangkat keras sudah dibuat dan terintegrasi dengan baik, dilakukan pengujian untuk memeriksa apakah sistem bekerja dengan benar dan layak untuk digunakan. Pengujian pertama yang dilakukan adalah validasi fitur aplikasi web oleh laboran untuk memastikan bahwa fitur yang dibuat sesuai dengan prosedur peminjaman alat yang semestinya (Nova, 2018: 1-14). Setelah validasi fitur selesai dilakukan, dilanjutkan white-box test dan black-box test. Pada pengujian Whitebox test dilakukan load testing dengan software Apache JMeter. Load testing dilakukan untuk memeriksa apakah semua halaman pada aplikasi web dapat dijangkau dengan latency yang rendah, terutama saat banyak pengguna sedang mengakses aplikasi web. Oleh sebab itu pada Apache JMeter dapat dilakukan simulasi dengan menentukan berapa jumlah pengguna yang mengakses halaman web, dan juga durasi pengguna tersebut mengakses halaman yang selanjutnya software akan melakukan load testing pada masing-masing halaman (Apache, 2021). Berbeda dengan white-box test, blackbox testing dilakukan sebagai pengujian terhadap aspek fungsional sistem. Black-box test dilakukan mengacu pada IBM Computer Usability Satisfaction Questionnaires untuk mengambil nilai hasil pengujian (Lewis, 1993). Terdapat beberapa sub-aspek yang diuji pada aspek Fungsional seperti pada Tabel 1.

Tabel 1. Aspek Fungsional yang Diuji pada Blackbox Test.

\begin{tabular}{|c|c|c|}
\hline Fungsi & Hasil & $\begin{array}{c}\text { Sub-Aspek } \\
\text { yang Terpenuhi }\end{array}$ \\
\hline $\begin{array}{l}\text { Launch dan } \\
\text { Close } \\
\text { Application }\end{array}$ & $\begin{array}{l}\text { Aplikasi web dapat } \\
\text { dijalankan dan dimatikan } \\
\text { tanpa adanya error. }\end{array}$ & Accurateness \\
\hline $\begin{array}{l}\text { Engine / } \\
\text { Stability }\end{array}$ & $\begin{array}{l}\text { Aplikasi dapat dijalankan } \\
\text { oleh user tanpa adanya } \\
\text { error/crash/freeze/stuck. }\end{array}$ & Accurateness \\
\hline $\begin{array}{l}\text { Navigasi } \\
\text { website }\end{array}$ & $\begin{array}{l}\text { Tombol-tombol pada } \\
\text { aplikasi web berfungsi } \\
\text { dengan benar. }\end{array}$ & Suitability \\
\hline $\begin{array}{l}\text { Tampilan } \\
\text { website }\end{array}$ & $\begin{array}{l}\text { User Interface baik, dan } \\
\text { aplikasi web dapat } \\
\text { digunakan oleh user } \\
\text { dengan mudah. }\end{array}$ & Compliance \\
\hline $\begin{array}{c}\text { Keamanan } \\
\text { data }\end{array}$ & $\begin{array}{l}\text { Fitur login dan content } \\
\text { management system } \\
\text { berjalan dengan baik, } \\
\text { hanya administrator } \\
\text { yang mempunyai akses } \\
\text { penuh pada keseluruhan } \\
\text { aplikasi web. }\end{array}$ & Security \\
\hline
\end{tabular}

Masing-masing fungsi pada aspek fungsional terdapat sub-aspek yang terpenuhi oleh sistem jika berjalan dengan baik. Stabilitas dan performa aplikasi web memenuhi sub-aspek accurateness, navigasi website yang bekerja dengan baik memenuhi sub-aspek suitability. Tampilan website diuji apakah mudah untuk digunakan oleh pengguna dan yang terakhir adalah keamanan data, data pada fitur akun laboran seharusnya tidak dapat diakses oleh mahasiswa. Pengujian dilakukan dengan kuesioner dan diisi oleh pengguna setelah menggunakan aplikasi web.

Pengujian dilakukan menggunakan kuesioner yang diisi oleh 15 mahasiswa dan / atau asisten laboratorium Prodi Teknik Elektro Unika Atma Jaya Jakarta setelah menggunakan aplikasi web. 15 orang mahasiswa dan / atau asisten terdiri dari mahasiswa lintas angkatan (angkatan 2017, 2018, dan 2019) Prodi Teknik Elektro yang masih melakukan praktikum laboratorium secara online. Mahasiswa yang masih menjalankan praktikum laboratorium merupakan responden yang tepat untuk kuesioner, karena dengan ini black-box test dapat memperoleh respon langsung dari praktikan laboratorium. Selanjutnya, nilai yang diperoleh dari kuesioner untuk masing-masing sub-aspek dijumlahkan untuk mendapatkan nilai total. Nilai total tersebut lalu dibagikan dengan nilai total yang diharapkan untuk mendapatkan persentase kelayakan seperti pada Persamaan (1):

$$
\text { Persentase Kelayakan }(\%)=\frac{\text { Penilaian Pengujian }}{\text { Total Nilai Pengujian }} \times 100
$$

Setelah persentase sudah diperoleh, dihitung juga jumlah nilai yang diperoleh dari kuesioner untuk mencari nilai rata-rata. Data pada kuesioner dianalisis menggunakan skala Likert agar hasil dan kesimpulan yang diperoleh lebih valid dan dapat diandalkan (Weksi, 2013: 127-133). Kesimpulan dari black-box test diambil dengan nilai rata-rata yang diperoleh dari kuesioner, lalu dikonversikan sesuai dengan kriteria pada Tabel 2., agar dapat memperoleh kesimpulan menggunakan data kuantitatif dari kuesioner.

Tabel 2. Kriteria Kesimpulan Black-box Testing.

\begin{tabular}{ccc}
\hline $\begin{array}{c}\text { Rerata Nilai } \\
(\boldsymbol{x})\end{array}$ & Kesimpulan & Catatan \\
\hline $0<x \leq 2$ & Tidak Baik & $\begin{array}{c}\text { Aplikasi web sama sekali } \\
\text { tidak dapat mencapai } \\
\text { tujuan fungsional yang } \\
\text { diharapkan. }\end{array}$ \\
\hline
\end{tabular}




\begin{tabular}{|c|c|c|}
\hline $\begin{array}{c}\text { Rerata Nilai } \\
(x)\end{array}$ & Kesimpulan & Catatan \\
\hline $2<x \leq 3$ & Kurang Baik & $\begin{array}{l}\text { Aplikasi web dapat } \\
\text { melakukan fungsi yang } \\
\text { diuji, namun belum } \\
\text { melakukannya secara } \\
\text { maksimal sesuai dengan } \\
\text { yang diinginkan. }\end{array}$ \\
\hline $3<x \leq 4$ & Baik & $\begin{array}{c}\text { Aplikasi web dapat } \\
\text { menjalankan fungsi yang } \\
\text { diuji dengan baik namun } \\
\text { masih dapat dilakukan } \\
\text { pengembangan. }\end{array}$ \\
\hline
\end{tabular}

\begin{tabular}{ccc}
\hline $\begin{array}{c}\text { Rerata Nilai } \\
(\boldsymbol{x})\end{array}$ & Kesimpulan & Catatan \\
\hline & & $\begin{array}{c}\text { Aplikasi web dapat } \\
\text { menjalankan fungsi yang } \\
\text { diuji dengan sempurna } \\
\text { sesuai dengan yang } \\
\text { diharapkan. }\end{array}$ \\
& Sangat Baik & . \\
& &
\end{tabular}

Alur kerja sistem untuk peminjaman barang secara online dijelaskan pada swimlane diagram yang dapat dilihat pada Gambar 4.

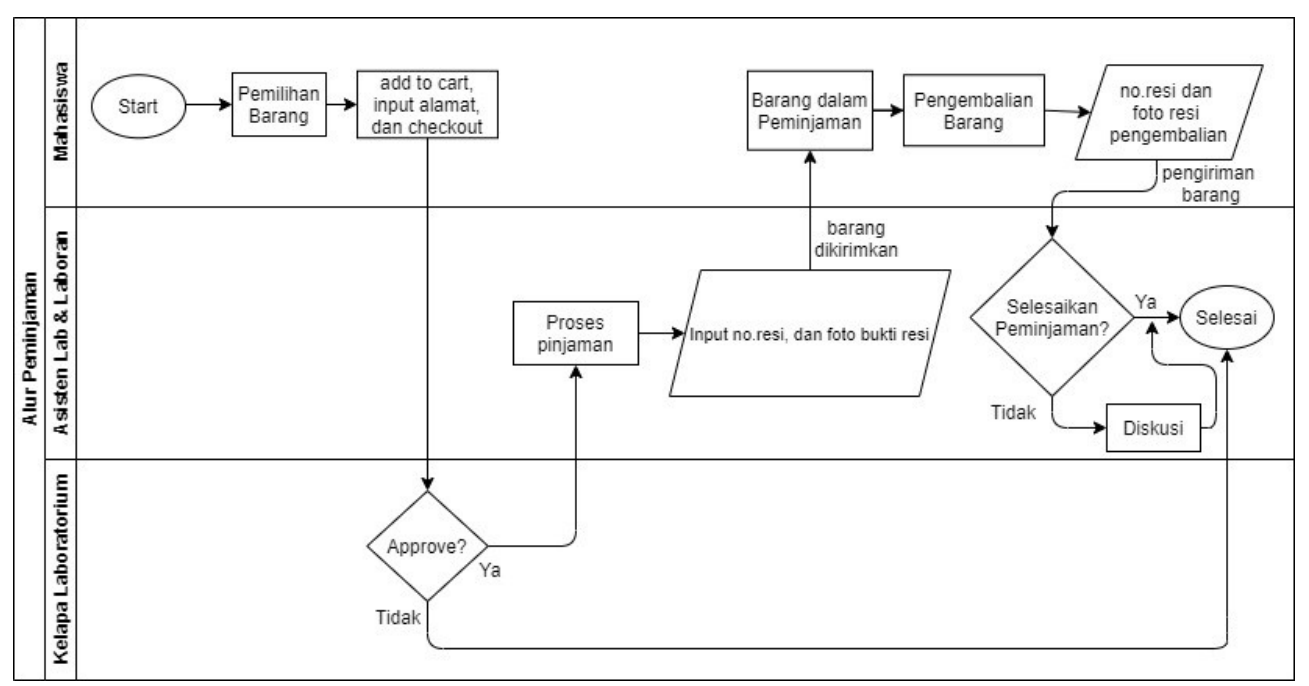

Gambar 4. Swimlane Diagram Alur Peminjaman Barang secara Online

Pertama-tama mahasiswa dapat memilih barang pada halaman daftar barang, memasukkannya ke dalam keranjang, masukan alamat pengiriman lalu checkout. Setelah checkout dilakukan, asisten laboratorium dan / atau laboran tidak bisa langsung memproses pinjaman tersebut, harus disetujui oleh kepala laboratorium terlebih dahulu. Jika kepala laboratorium menyetujui, maka pinjaman dapat diproses dan jika tidak disetujui pinjaman akan langsung dibatalkan. Saat asisten laboratorium atau laboran menekan tombol 'proses', akan diminta memasukan data pengiriman yaitu tipe kurir, nomor resi, dan bukti foto resi. Setelah data tersebut berhasil di-submit, status pinjaman akan berubah menjadi 'dalam peminjaman' dan mahasiswa dapat melihat nomor resi dan bukti foto resi pada halaman rincian pesanan akun. Sebelum melewati batas tanggal pengembalian, mahasiswa wajib mengembalikan barang dengan mengirimkan barang, lalu menuju ke halaman rincian pinjaman pada aplikasi web dan tekan tombol 'retur'. Untuk proses pengembalian mahasiswa cukup masukan nomor resi pengembalian dan foto bukti resi tersebut. Saat barang sudah sampai dan asisten laboratorium / laboran sudah menerimanya, maka dapat menekan tombol 'selesaikan pinjaman' pada halaman rincian pinjaman untuk menyelesaikan transaksi pinjaman.

Untuk peminjaman barang di tempat, mahasiswa dapat mengunjungi laboratorium dan mengakses halaman 'peminjaman di tempat' pada aplikasi web di PC laboratorium, tentunya dengan izin dari asisten laboratorium atau laboran. Pada halaman tersebut mahasiswa diminta untuk mengisi data diri, kondisi barang, dan barang yang dipinjam. Sama seperti peminjaman secara online, pinjaman harus disetujui oleh kepala laboratorium terlebih dahulu sebelum barang dapat diserahkan kepada mahasiswa. Jika sudah disetujui maka asisten laboratorium dan / atau laboran dapat tapping RFID untuk mengubah stok barang lalu menyerahkannya ke mahasiswa. Saat barang sudah digunakan dan dikembalikan, asisten laboratorium dan / atau laboran dapat mengakses halaman 'scan barang masuk' pada aplikasi web. Tag pada barang perlu didekatkan 
ke reader untuk melakukan tapping. Setelah nilai UID muncul pada halaman web, asisten laboratorium atau laboran dapat memilih transaksi lalu tekan tombol 'submit'. Setelah sudah menekan tombol 'submit' transaksi pinjaman akan diselesaikan dan status stok barang kembali menjadi tersedia. Alur peminjaman di tempat dapat dilihat pada Gambar 5.

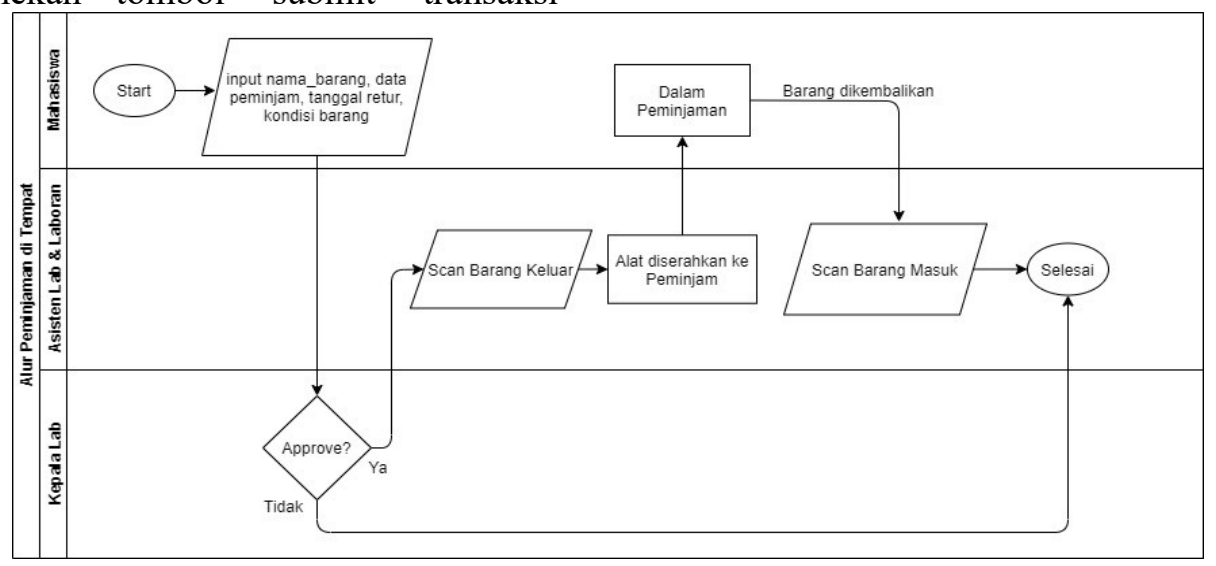

Gambar 5. Swimlane diagram alur peminjaman di tempat

Selain proses pinjaman, laboran juga dapat melakukan registrasi barang baru dan mengatur data barang. Hal ini dikarenakan laboran mempunyai role tertinggi sebagai administrator atau super-admin yang mempunyai akses ke semua fitur.

\section{HASIL DAN PEMBAHASAN}

Untuk mendapat hasil pengujian yang lebih akurat dan mencakup keseluruhan sistem, pengujian dilakukan pada perangkat keras dan perangkat lunak. Pengujian perangkat lunak dilakukan pada bagian internal (white-box test) dan eksternal (black-box test) sistem, namun sebelum itu dilakukan validasi fitur oleh laboran terlebih dahulu. Sedangkan pengujian tapping dilakukan terhadap perangkat keras yang digunakan.

Pada pengujian perangkat keras, jarak maksimal pembacaan tag RFID dari reader diperoleh agar UID dapat dikirimkan dari mikrokontroler ke dalam database. Proses pembacaan Tag RFID dengan bantuan tampilan Serial Monitor Arduino IDE dapat dilihat pada Gambar 6.

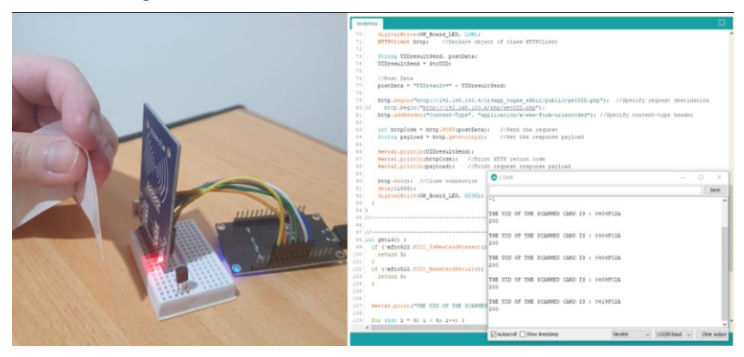

Gambar 6. Pembacaan Tag RFID \& Tampilan
Serial Monitor Arduino IDE

Pada setiap tag RFID terdapat memori yang menyimpan nilai UID. Reader RFID mengeluarkan medan elektromagnetik dengan signal generator. Saat tag didekatkan ke reader, microchip pada tag menerima daya dan nilai UID dapat dikirimkan ke reader melalui backscatter. Hasil pengujian tapping RFID dapat dilihat pada Tabel 3.

Tabel 3. Hasil Pengujian Tapping RFID

\begin{tabular}{cc}
\hline Jarak Scan Tag RFID & Pembacaan \\
\hline $0 \mathrm{~cm}$ & Terbaca \\
$1 \mathrm{~cm}$ & Terbaca \\
$2 \mathrm{~cm}$ & Terbaca \\
$3 \mathrm{~cm}$ & Tidak Terbaca \\
$4 \mathrm{~cm}$ & Tidak Terbaca \\
$5 \mathrm{~cm}$ & Tidak Terbaca
\end{tabular}

Dapat dilihat pada Tabel 3, tag RFID hanya akan merespon saat jaraknya dengan reader tidak melebihi $2 \mathrm{~cm}$. Selama jarak tag dengan reader masih dalam jarak $2 \mathrm{~cm}$, UID pada tag RFID dapat diterima oleh mikrokontroler untuk ditampilkan pada serial monitor seperti pada Gambar 6. UID yang diterima selanjutnya dikirimkan ke database untuk ditampilkan pada form di halaman web, agar dapat melakukan tapping untuk mengubah status ketersediaan barang.

Pada pengujian, saat tag RFID dapat 
dibaca oleh reader, digunakan query builder class dari CodeIgniter 4 untuk mencari data barang yang nilai RFID-nya sesuai pada database. Setelah nama barang dan status sudah ditemukan, data dapat ditampilkan pada halaman web seperti pada Gambar 7. Dengan demikian, integrasi perangkat keras dan aplikasi web (dengan framework CodeIgniter 4) bekerja dengan baik.

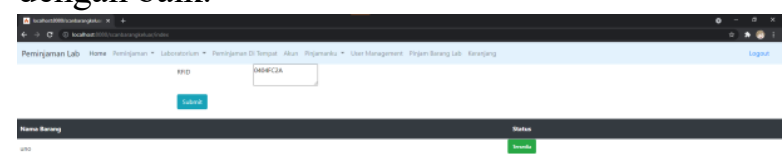

Gambar 7. Hasil Pengujian Tapping pada Website

Setelah sistem dibuat, fitur-fitur yang ada diuji dan divalidasi terlebih dahulu oleh laboran untuk memastikan bahwa fitur yang diperlukan sudah ada dan dapat bekerja dengan semestinya sesuai dengan prosedur laboratorium Teknik Elektro Unika Atma Jaya Jakarta. Pada pengujian validasi fitur terdapat dua siklus, pada pengujian pertama fitur yang diuji adalah seperti pada Tabel 8 dimana Laboran mencoba masing-masing fitur pada aplikasi web dan memberikan persetujuan. Namun setelah melakukan pengujian pertama, laboran merasa masih ada fitur yang kurang dan belum cocok dengan prosedur yang sebenarnya. Aplikasi web masih memerlukan revisi seperti penggunaan nilai RFID sebagai primary key untuk tabel barang. Fitur persetujuan kepala laboratorium yang dianggap penting pada prosedur peminjaman barang juga belum ada pada aplikasi web. Terdapat pula beberapa fitur tambahan yang diminta oleh laboran untuk mempermudah penggunaan aplikasi web. Oleh sebab itu dilakukan revisi dan pengembangan fitur seperti pada Tabel 5. Setelah semua fitur diuji dan disetujui oleh laboran, sistem peminjaman barang sudah sesuai dengan prosedur yang digunakan pada skenario aslinya. Tabel 4. Validasi Pengujian Sistem oleh Laboran

\begin{tabular}{lc}
\hline Fitur & Diuji \\
\hline $\begin{array}{l}\text { Login dan Register akun administrator, asisten } \\
\text { laboratorium, kepala laboratorium, dan } \\
\text { mahasiswa. }\end{array}$ & $\checkmark$ \\
$\begin{array}{l}\text { Perbedaan session antara level akun. Fitur yang } \\
\text { dapat digunakan untuk masing-masing level } \\
\text { akun berbeda, dimana Administrator } \\
\text { mempunyai akses fitur keseluruhan. }\end{array}$ & $\checkmark$ \\
$\begin{array}{l}\text { [Admin, Aslab, Kalab] Tampilan daftar } \\
\text { peminjaman barang online. }\end{array}$ & $\checkmark$ \\
\end{tabular}

\begin{tabular}{|c|c|}
\hline Fitur & Diuji \\
\hline $\begin{array}{l}\text { [Admin, Aslab, Kalab] Tampilan daftar } \\
\text { peminjaman di tempat. }\end{array}$ & $\checkmark$ \\
\hline $\begin{array}{l}\text { [Admin, Aslab, Kalab] Tombol 'Detail' pada } \\
\text { daftar pinjaman online untuk menampilkan } \\
\text { rincian pinjaman. }\end{array}$ & $\checkmark$ \\
\hline $\begin{array}{l}\text { [Admin, Aslab] Tombol 'Proses' untuk proses } \\
\text { pesanan dengan memasukan tipe kurir, nomor } \\
\text { resi, dan foto bukti resi. }\end{array}$ & $\checkmark$ \\
\hline $\begin{array}{l}\text { [Admin, Aslab] Pilihan 'Peminjaman di } \\
\text { Tempat' pada navigation bar untuk mahasiswa } \\
\text { melakukan pinjaman langsung di laboratorium. } \\
\text { Dengan mengisi form data diri dan tanggal } \\
\text { pengembalian. }\end{array}$ & $\checkmark$ \\
\hline $\begin{array}{l}\text { [Admin, Aslab, Kalab] Tampilan daftar barang } \\
\text { pada masing-masing laboratorium. }\end{array}$ & $\checkmark$ \\
\hline $\begin{array}{l}\text { [Admin, Aslab] Halaman untuk scan barang } \\
\text { masuk. }\end{array}$ & $\checkmark$ \\
\hline $\begin{array}{l}\text { [Admin, Aslab] Halaman untuk scan barang } \\
\text { keluar }\end{array}$ & $\checkmark$ \\
\hline $\begin{array}{l}\text { [Admin] Halaman untuk registrasi barang baru. } \\
\text { Dengan tapping RFID dan input kode barang. }\end{array}$ & $\checkmark$ \\
\hline $\begin{array}{l}\text { [Admin] Halaman User Management, } \\
\text { menampilkan list akun yang sudah terdaftar } \\
\text { serta role masing-masing akun. }\end{array}$ & $\checkmark$ \\
\hline $\begin{array}{l}\text { Halaman Akun, menampilkan informasi akun } \\
\text { yang sedang login. }\end{array}$ & $\checkmark$ \\
\hline $\begin{array}{l}\text { [Mahasiswa] Halaman 'Transaksi Sedang } \\
\text { Berjalan' untuk menampilkan peminjaman } \\
\text { yang sedang dilakukan. }\end{array}$ & $\checkmark$ \\
\hline $\begin{array}{l}\text { [Admin, Mahasiswa] Halaman 'Pinjam Barang } \\
\text { Lab' yang menampilkan list barang } \\
\text { laboratorium dengan tombol 'Masukan } \\
\text { Keranjang'. }\end{array}$ & $\checkmark$ \\
\hline $\begin{array}{l}\text { [Mahasiswa] Halaman } \\
\text { menampilkan list beranjang', } \\
\text { dimasukan ke dalam keranjang. }\end{array}$ & $\checkmark$ \\
\hline $\begin{array}{l}\text { [Mahasiswa] Halaman 'Lanjut Checkout' } \\
\text { terdapat form untuk memasukan alamat } \\
\text { pengiriman dan tanggal pengembalian barang, } \\
\text { wajib diisi sebelum checkout peminjaman. }\end{array}$ & $\checkmark$ \\
\hline $\begin{array}{l}\text { [Mahasiswa] Halaman 'Checkout', } \\
\text { menampilkan rincian peminjaman dan tombol } \\
\text { checkout untuk melakukan peminjaman. } \\
\text { Setelah tombol checkout ditekan, pesanan akan } \\
\text { masuk ke daftar peminjaman pada akun Aslab } \\
\text { dan Kalab. }\end{array}$ & $\checkmark$ \\
\hline $\begin{array}{l}\text { [Mahasiswa] Halaman rincian pinjamanku, } \\
\text { menampilkan rincian dan juga status } \\
\text { peminjaman. Nomor dan bukti resi kurir yang } \\
\text { sudah dimasukan oleh asisten laboratorium atau } \\
\text { laboran juga ditampilkan. }\end{array}$ & $\checkmark$ \\
\hline
\end{tabular}




\begin{tabular}{lll}
\hline Fitur & Diuji \\
\hline [Mahasiswa] Tombol 'Retur' untuk proses & \\
pengembalian barang dengan form untuk \\
memasukan tipe kurir, nomor resi, dan foto \\
bukti resi.
\end{tabular}

Tabel 5. Validasi pengujian fitur yang telah direvisi

\begin{tabular}{lc}
\multicolumn{1}{c}{ dan dikembangkan } & Diuji \\
\hline Fitur & $\checkmark$ \\
\hline $\begin{array}{l}\text { Primary Key pada tabel barang direvisi, kolom } \\
\text { 'RFID' sebagai primary key. }\end{array}$ & \\
& \\
Menambahkan fitur untuk update nama barang \\
dan kode barang pada daftar barang laboratorium \\
(untuk administrator).
\end{tabular}

Setelah fitur disetujui, dilakukan Whitebox test guna memeriksa apakah bagian internal sistem bekerja dengan baik. Pada fase Whitebox test dilakukan Load testing pada setiap halaman aplikasi web menggunakan software Apache JMeter.

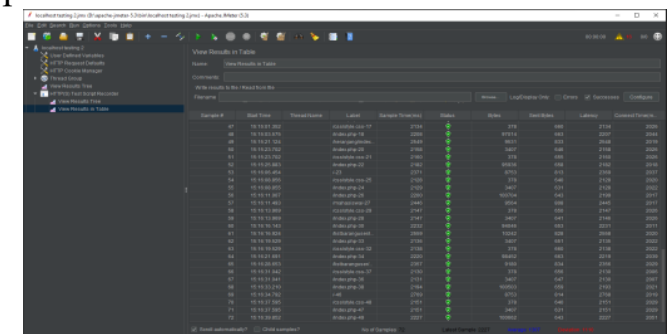

Gambar 8. Tampilan Software Apache JMeter (Apache, 2021)

Apache JMeter bekerja dengan mensimulasikan masing-masing halaman dengan jumlah pengunjung yang diatur sebelum pengujian, dan hasil pengujian berupa nilainilai respon dari halaman web. Pada simulasi pengujian ini jumlah pengguna diatur sebanyak 10 orang, yaitu setengah dari rata-rata jumlah mahasiswa masing-masing angkatan Prodi Teknik Elektro Unika Atma Jaya Jakarta. Hasil pengujian dirangkum pada Tabel 6 yang berisi hasil load testing dengan kolom Label / Halaman yang diuji, Sample Time, Bytes, dan Status.

Tabel 6. Hasil Pengujian Load Testing

\begin{tabular}{|c|c|c|c|}
\hline Label & $\begin{array}{c}\text { Sample } \\
\text { Time } \\
(\mathrm{ms})\end{array}$ & $\begin{array}{l}\text { Byte } \\
\text { s }\end{array}$ & Status \\
\hline $\begin{array}{l}\text { http://localhost: } 8080 / \text { index } / \text { lo } \\
\text { gin }\end{array}$ & 2223 & 4722 & $\begin{array}{c}\text { Code: } \\
200 \\
\text { OK }\end{array}$ \\
\hline http://localhost:8080/logout & 2254 & 777 & $\begin{array}{c}\text { Code: } \\
200 \\
\text { OK }\end{array}$ \\
\hline http://localhost:8080/index & 2208 & $\begin{array}{c}1010 \\
84\end{array}$ & $\begin{array}{c}\text { Code: } \\
200 \\
\text { OK }\end{array}$ \\
\hline $\begin{array}{c}\text { http://localhost:8080/listbaran } \\
\text { guser/ }\end{array}$ & 2962 & $\begin{array}{c}1088 \\
2\end{array}$ & $\begin{array}{c}\text { Code: } \\
200 \\
\text { OK }\end{array}$ \\
\hline $\begin{array}{c}\text { http://localhost:8080/keranjan } \\
\text { g }\end{array}$ & 2520 & $\begin{array}{c}1194 \\
3\end{array}$ & $\begin{array}{c}\text { Code: } \\
200 \\
\text { OK }\end{array}$ \\
\hline $\begin{array}{l}\text { http://localhost:8080/keranjan } \\
\text { g/lanjutkeranjang }\end{array}$ & 2416 & $\begin{array}{c}1169 \\
1\end{array}$ & $\begin{array}{c}\text { Code: } \\
200 \\
\text { OK }\end{array}$ \\
\hline $\begin{array}{c}\text { http://localhost:8080/keranjan } \\
\text { g/checkout }\end{array}$ & 2347 & $\begin{array}{c}1276 \\
6\end{array}$ & $\begin{array}{c}\text { Code: } \\
200 \\
\text { OK }\end{array}$ \\
\hline $\begin{array}{c}\text { http://localhost:8080/pinjama } \\
\text { nku }\end{array}$ & 2392 & $\begin{array}{c}1039 \\
5\end{array}$ & $\begin{array}{c}\text { Code: } \\
200 \\
\text { OK }\end{array}$ \\
\hline $\begin{array}{c}\text { http://localhost: } 8080 / \text { pinjama } \\
\text { nku/pengembalian }\end{array}$ & 2355 & $\begin{array}{c}1175 \\
9\end{array}$ & $\begin{array}{c}\text { Code: } \\
200 \\
\text { OK }\end{array}$ \\
\hline $\begin{array}{l}\text { http://localhost:8080/menung } \\
\text { gupersetujuan }\end{array}$ & 2222 & 9962 & $\begin{array}{c}\text { Code: } \\
200 \\
\text { OK }\end{array}$ \\
\hline $\begin{array}{l}\text { http://localhost: } 8080 / \text { persetuj } \\
\text { uanoffline }\end{array}$ & 2435 & 9591 & $\begin{array}{c}\text { Code: } \\
200 \\
\text { OK }\end{array}$ \\
\hline $\begin{array}{l}\text { http://localhost: } 8080 / \text { peminja } \\
\operatorname{man}\end{array}$ & 2334 & $\begin{array}{c}1145 \\
2\end{array}$ & $\begin{array}{c}\text { Code: } \\
200 \\
\text { OK }\end{array}$ \\
\hline $\begin{array}{l}\text { http://localhost: } 8080 / \text { peminja } \\
\text { man/proses }\end{array}$ & 2376 & $\begin{array}{c}1039 \\
2\end{array}$ & $\begin{array}{c}\text { Code: } \\
200 \\
\text { OK }\end{array}$ \\
\hline $\begin{array}{l}\text { http://localhost:8080/pinjamo } \\
\text { ffline }\end{array}$ & 2298 & $\begin{array}{c}1424 \\
2\end{array}$ & $\begin{array}{c}\text { Code: } \\
200 \\
\text { OK }\end{array}$ \\
\hline $\begin{array}{l}\text { http://localhost: } 8080 / \text { laborato } \\
\text { rium }\end{array}$ & 2401 & $\begin{array}{c}1352 \\
7\end{array}$ & $\begin{array}{c}\text { Code: } \\
200 \\
\text { OK }\end{array}$ \\
\hline
\end{tabular}

Dari hasil load testing yang diperoleh 
pada Tabel 7, terlihat bahwa respon dari semua halaman pada aplikasi web menghasilkan kode respon 200 dengan status 'OK'. Dengan kata lain, halaman-halaman dapat digunakan dengan semestinya dan dapat dibuka oleh pengguna.

Black-box test berfokus pada bagian eksternal sistem, seperti aspek fungsional sistem, navigasi pada aplikasi web dan juga tampilan halaman web. Sub-aspek yang teruji adalah accuracy, suitability, compliance dan security. Hasil dari black-box test disimpulkan dari tanggapan dan nilai rata-rata kuesioner yang diisi oleh 15 mahasiswa dan / atau asisten laboratorium, lalu dikonversi sesuai dengan kriteria yang ditentukan. Hasil pengujian yang diperoleh dapat dilihat pada Tabel 7 dan Tabel 8. Tabel 7 menjelaskan hasil survey secara deskriptif dan Tabel 7 menampilkan nilai yang diperoleh dari kuesioner.

Tabel 7. Hasil Tanggapan Pengujian Black-box Text.

\begin{tabular}{ccccc}
\hline \multirow{2}{*}{ Fungsi } & \multicolumn{4}{c}{ Tanggapan } \\
\cline { 2 - 5 } & $\begin{array}{c}\text { Tidak } \\
\text { Baik }\end{array}$ & $\begin{array}{c}\text { Kurang } \\
\text { Baik }\end{array}$ & Baik & $\begin{array}{c}\text { Sangat } \\
\text { Baik }\end{array}$ \\
\hline $\begin{array}{c}\text { Launch dan Close } \\
\text { Application }\end{array}$ & $0 \%$ & $0 \%$ & $26,70 \%$ & $73,30 \%$ \\
Engine/ Stability & $0 \%$ & $0 \%$ & $40,00 \%$ & $60,00 \%$ \\
Navigasi website & $0 \%$ & $6,70 \%$ & $53,30 \%$ & $40,00 \%$ \\
Tampilan website & $0 \%$ & $53,30 \%$ & $40,00 \%$ & $6,70 \%$ \\
Keamanan data & $0 \%$ & $0 \%$ & $80,00 \%$ & $20,00 \%$ \\
Rata-rata & $0 \%$ & $12,00 \%$ & $48,00 \%$ & $40,00 \%$
\end{tabular}

Tabel 7 merepresentasikan distribusi tanggapan yang diperoleh dari kuesioner. Terdapat empat nilai tanggapan yaitu tidak baik, kurang baik, baik, dan sangat baik untuk masing-masing fungsi yang diuji. Distribusi tanggapan ditampilkan dalam bentuk persentase dari jumlah responden. Setelah itu dicari persentase rata-rata seperti pada baris paling bawah di Tabel 7 sebagai representasi tanggapan keseluruhan sistem. Berdasarkan pada data Tabel 7, dapat dilihat sebagian besar responden setuju bahwa fungsi Launch dan Close Application serta Engine / Stability berada dalam kategori "Sangat Baik" dan juga fungsi Navigasi Website dan Keamanan Data dalam kategori "Baik". Namun, Sebagian besar juga setuju bahwa Tampilan Website berada dalam kategori "Kurang Baik" dimana pengoperasian UI Website masih kurang dari harapan.

Selanjutnya, rata-rata nilai tanggapan yang diperoleh dari kuesioner dihitung untuk diambil kesimpulan. Seperti pada Tabel 7 masing-masing fungsi memiliki tanggapan yang diisi oleh responden, yaitu 'Tidak Baik', 'kurang baik', 'baik', dan 'sangat baik'. Pada Tabel 7 masing-masing tanggapan diberikan bobot nilai. Tanggapan 'Tidak Baik' bernilai 1, 'kurang baik' berbobot 2, tanggapan 'baik' berbobot 3, dan 'sangat baik' bernilai 4. Nomor yang di bawah kolom 'nilai' adalah distribusi jumlah responden untuk masing-masing nilai. Baris 'jumlah' menampilkan jumlah responden untuk masing-masing tanggapan sebelum dikalikan dengan bobot nilai. Setelah jumlah responden sudah dikalikan dengan bobot masing-masing tanggapan, seluruh nilai dari empat buah tanggapan dijumlahkan dan hasilnya tertulis pada baris 'Total'.

Terkait dengan pengambilan kesimpulan, diambil nilai rata-rata per fungsi dari total nilai yang diperoleh. Nilai rata-rata diperoleh dari total nilai dibagi dengan jumlah nilai semua fungsi, menghasilkan rerata nilai sebesar 3,28. Selanjutnya, rerata nilai dikonversikan mengacu pada Tabel 3. Dengan demikian aplikasi web yang mendapat rerata nilai sebesar 3,28 dari responden masuk dalam kategori Baik dengan persentase kelayakan sistem yang diperoleh sebesar $\mathbf{8 2 \%}$. Hasil penilaian pngujian Blackbox test dapat dilihat pada Tabel 8 .

Tabel 8. Hasil Penilaian Pengujian Black-box Test

\begin{tabular}{|c|c|c|c|c|c|}
\hline \multirow{3}{*}{ Fungsi } & \multirow[t]{3}{*}{ Sub Aspek } & \multicolumn{4}{|c|}{ Nilai } \\
\hline & & 1 & 2 & 3 & 4 \\
\hline & & $\begin{array}{l}\text { (Tidak } \\
\text { Baik) }\end{array}$ & $\begin{array}{c}\text { (Kurang } \\
\text { Baik) }\end{array}$ & (Baik) & $\begin{array}{c}\text { (Sangat } \\
\text { Baik) }\end{array}$ \\
\hline $\begin{array}{c}\text { Launch } \\
\text { dan Close } \\
\text { Application }\end{array}$ & Accurateness & 0 & 0 & 4 & 11 \\
\hline $\begin{array}{l}\text { Engine / } \\
\text { Stability }\end{array}$ & Accurateness & 0 & 0 & 6 & 9 \\
\hline $\begin{array}{l}\text { Navigasi } \\
\text { Website }\end{array}$ & Suitability & 0 & 1 & 8 & 6 \\
\hline $\begin{array}{l}\text { Tampilan } \\
\text { website }\end{array}$ & Compliance & 0 & 8 & 6 & 1 \\
\hline $\begin{array}{c}\text { Keamanan } \\
\text { data }\end{array}$ & Security & 0 & 0 & 12 & 3 \\
\hline Jumlah & & 0 & 9 & 36 & 30 \\
\hline Jumlah x S & or Nilai & 0 & 18 & 108 & 120 \\
\hline Total & & & & & \\
\hline Rerata Nila & & & & & \\
\hline \% Kelayak & Sistem & & & & \\
\hline Kesimpulan & & & & & \\
\hline
\end{tabular}

Dengan demikian, dapat disimpulkan bahwa aplikasi web dapat menjalankan fungsi yang diuji dengan baik namun masih dapat dilakukan pengembangan. Dari hasil pengujian sistem yang diperoleh, aplikasi web dinyatakan 
sudah mempunyai fitur yang cukup dan memiliki prosedur yang sesuai untuk peminjaman alat laboratorium. Maka dapat digunakan pada laboratorium Program Studi Teknik Elektro Unika Atma Jaya Jakarta.

Framework CodeIgniter 4 sangat membantu dalam proses kerja fitur yang ada pada aplikasi web, terutama pada tapping tag barang dan pengelolaan form. CodeIgniter 4 memungkinkan pertukaran data yang lebih mudah dengan database agar fitur dapat dikembangkan lebih cepat dan bekerja dengan baik. Sehingga dengan fitur pada aplikasi web yang dapat bekerja dan sudah sesuai dengan prosedur laboratorium, dapat dikatakan bahwa aplikasi web berhasil dikembangkan dengan framework CodeIgniter 4.

\section{SIMPULAN}

Dari perancangan dan hasil tiga pengujian (validasi fitur, white-box testing, dan black-box testing) yang sudah dilakukan, dapat diambil kesimpulan bahwa fitur yang ada pada aplikasi web sudah sesuai dengan kebutuhan prosedur peminjaman alat laboratorium pada kampus. Fitur yang ada pada aplikasi web diuji dan divalidasi oleh laboran dan sudah sesuai berdasarkan fungsionalitasnya dengan prosedur peminjaman pada laboratorium. Aplikasi web berhasil dikembangkan dengan framework CodeIgniter 4 pada pengembangan fitur yang diperlukan serta dapat bekerja dengan baik. Integrasi perangkat keras (RFID reader) dengan perangkat lunak (aplikasi web) bekerja dengan baik sesuai dengan hasil dari pengujian tapping RFID. Selama jarak tag tidak melebihi $2 \mathrm{~cm}$ dari reader, nilai UID pada tag terbaca saat dilakukan tapping dan dapat dicari data barang pada database menggunakan query builder class CodeIgniter 4. Data barang dapat ditampilkan pada halaman web setelah diperoleh dari database. Pengujian load testing pada white-box test menghasilkan kode respon 200 untuk masing-masing halaman pada aplikasi web, sehingga respon koneksi antara client dan server berjalan dengan baik. Terakhir, dari hasil pengujian black-box test guna memeriksa fungsionalitas pada aplikasi web dan juga menguji penerapan sistem pada laboratorium diperoleh nilai rata-rata sebanyak 3,28 dengan kata lain fungsionalitas aplikasi web dapat dinilai 'Baik' oleh responden dengan persentase kelayakan sistem sebanyak $82 \%$. Dengan demikian aplikasi web dapat digunakan untuk mengatasi keterbatasan peminjaman alat laboratorium universitas, agar mahasiswa dapat melakukan peminjaman alat laboratorium secara online.

\section{DAFTAR RUJUKAN}

Apache, Apache
(https://jmeter.apache.org/, diakses 18
Mei 2021).

Arikunto Suharsimi. 2014. Prosedur Penelitian Suatu Pendekatan Praktik. Jakarta: Rhineka Cipta.
Arduino, Arduino IDE. (https://www.arduino.ccl, diakses 24 Juni 2021).

Ariesta.R, Supartono. 2011. Pengembangan Perangkat Perkuliahan Kegiatan Laboratorium Fisika Dasar II Berbasis Inkuiri Terbimbing Untuk Meningkatkan Kerja Ilmiah Mahasiswa. Jurnal Pendidikan Fisika Indonesia. 2011 (7): 62-68.

Bagui, S and Earp, R. 2011. Database Design Using Entity-Relationship Diagrams. Ohio: CRC Press.

Chaudhuri, A.N. 2005. The Art of Programming Through Flowcharts \& Algorithms. New Delhi: Firewall Media.

CodeIgniter, CodeIgniter4 User Guide. (https://https://codeigniter.com/user guid e/index.html/, diakses 8 Juni 2021).

Duckett, J. 2011. HTML and CSS: Design and Build Websites. New Jersey: Wiley.

Fenny Meilia, Jatniko Nur Mutaqin dan Tri Pujadi, T. 2014. Diagram Swimlane. Binus University Articles.

Fielding, R.; Gettys, J.; Mogul, J.; Frystyk, H.; Masinter, L.; Leach, P.; Berners-Lee, T. (June 1999). Hypertext Transfer Protocol - HTTP/1.1. Request For Comments 2616. Information Sciences Institute.

Hathaway, T and Hathaway, A. 2016. Data Flow Diagrams - Simply Put!: Process Modeling Techniques for Requirements 
Elicitation and Workflow Analysis (Advanced Business Analysis Topics). California: CreateSpace Publishing.

Kartika Pertiwi, Kodrat I.S, dan Maman Somantri. 2013. Sistem Informasi Manajemen Aset Di Fakultas Teknik Universitas Diponegoro. Transien. 2013 (2): 40-44.

Laudon, K.C and Laudon, J.P. 2017. Management Information Systems. London: Pearson.

Lewis,J.R. 1993. IBM Computer Usability Satisfaction Questionnaires: Psychometric Evaluation and Instructions for Use. Boca Raton: IBM Corporation.

Molinaro, A. 2006. SQL Cookbook: Query Solutions and Techniques for Database Developers. California: O'Reilly Media, Inc.

Muhammad Syahwil. 2013. Panduan Mudah Simulasi dan Praktek Mikrokontroler Arduino. Yogyakarta: Andi Offset Yogyakarta..
Myers. G.J. 2004. The Art of Software Testing. New Jersey: John Wiley \& Sons, Inc.

Naim Wochmawati dan Sholikhuddin Rosyidi. 2018. Sistem Informasi Aset Laboratorium Jurusan Teknik Informatika Universitas Negeri Surabaya. Jurnal Manajemen Informatika, 8(2): 105-110.

Nova Eka Budiyanta. 2018. Pengembangan Kelayakan Sistem Informasi Manajemen Untuk Workshop dan Laboratorium. Jurnal Elektro Unika Atma Jaya, 11(1): $1-14$.

Weksi Budiaji. 2013. Skala Pengukuran dan Jumlah Respon Skala Likert. Jurnal Ilmu Pertanian dan Perikanan, 2(2): 127-133.

Yuda Edi Purnomo. 2017. Sistem Peminjaman Buku Berbasis RFID. Publikasi Ilmiah. Surakarta: Fakultas Komunikasi dan Informatika Universitas Muhammadiyah Surakarta. 